\title{
Plantas tóxicas para ruminantes e eqüídeos no Norte Piauiense $^{1}$
}

\author{
Gustavo W.S. Mello², Diego M. Oliveira ${ }^{3}$, Ciro J.S. Carvalho ${ }^{4}$, Lidiany Viana \\ Pires $^{4}$, Francisco A.L. Costa ${ }^{5}$, Franklin Riet-Correa ${ }^{3}$ e Silvana M.M. Silva ${ }^{5^{*}}$
}

\begin{abstract}
Mello G.W.S, Oliveira D.M., Carvalho C.J.S., Pires L.V., Costa F.A.L., Riet-Correa F. \& Silva S.M.M. 2010. [Toxic plants for ruminants and equidae in Northern Piauí.] Plantas tóxicas para ruminantes e eqüídeos no Norte Piauiense. Pesquisa Veterinária Brasileira 30(1):1-9. Universidade Federal do Piauí, Campus Agrícola da Socopo, Teresina, PI 64049-550, Brazil. E-mail: sissivet@yahoo.com.br

The objective of this study was to survey toxic plants for ruminants and equidae in northern Piauí. Seventy one persons were interviewed, including farmers, veterinary practitioners, agronomists, and agrarian technicians from 16 municipalities, performing at least four interviews in each municipality. The most common plant mentioned as a cause of poisoning was Ipomoea asarifolia, which is a well known cause of tremogenic disease in ruminants. Stryphnodendron coriaceum which causes digestive signs was referred as a common cause of death, and is probably the plant that causes most cattle deaths in the region. Enterolobium contortisiliquum was also mentioned as a frequent cause of digestive signs, abortion and photosensitization in cattle. Outbreaks of nephrosis caused by Thiloa glaucocarpa are frequent at the beginning of the raining season. Poisoning by the cyanogenic plants Manihot spp. e Piptadenia macrocarpa are a cause of peracute deaths. Other plants mentioned as toxic were Buchenavia tomentosa, Caesalpinia sp., Brunfelsia sp., Luetzelburgia sp., Hybantus ipecaconha, Phisalys angulata, and Spondias luta. Farmers report that goats are poisoned by the ingestion of the pods of Luetzelburgia sp., which causes digestive signs and death. The ingestion of the fruits of Buchenavia tomentosa is associated with digestive signs and and abortion in ruminants. Brunfelsia sp. is mentioned as a cause of nervous signs at the start of the raining season and donkeys are apparently more affected. The consumption of the fruits of Spondias luta are associated with diarrhea in goats. Recent unpublished experiments demonstrated the toxicity of Brunfelsia sp. as a cause of nervous signs and of Luetzelburgia $\mathrm{sp}$. as a cause of digestive signs in goats. Experiments with other plants are necessary to confirm their toxicity.
\end{abstract}

INDEX TERMS: Poisonous plants, northeastern Brazil, Ipomoea asarifolia, Stryphnodendron coriaceum, Enterolobium contortisiliquum, Thiloa glaucocarpa, cyanogenic plants, plant poisoning.

\footnotetext{
${ }^{1}$ Recebido para publicação em 22 de abril 2009.

Aceito para publicação em 14 de agosto de 2009.

2 Pós-Graduando de Mestrado em Ciência Animal, Centro de Ciências Agrárias, Universidade Federal do Piauí (UFPI), Campus Agrícola da Socopo, s/n, Teresina, PI 64049-550, Brasil.

${ }^{3}$ Hospital Veterinário, Centro de Saúde e Tecnologia Rural, Universidade Federal de Campina Grande, Campus de Patos, Patos, PB 58700000, Brasil.

${ }^{4}$ Bolsista de Iniciação Científica, UFPI, Campus Agrícola da Socopo, s/n, Teresina, PI 64049-550, Brasil.

${ }^{5}$ Universidade Federal do Piauí, Campus Agrícola da Socopo, s/n, Teresina, PI 64049-550, Brasil. *Autor para correspondência: sissivet@yahoo.com.br
}

RESUMO.- Este trabalho teve por objetivo realizar um levantamento sobre as plantas tóxicas para ruminantes e equídeos na Mesorregião Norte do Piauí. Foram feitas 71 entrevistas a médicos veterinários, engenheiros agrônomos, técnicos agrícolas e produtores de 16 municípios, entrevistando pelo menos quatro pessoas por município. As plantas comprovadamente tóxicas que foram apontadas com maior frequência na região estudada foram Ipomoea asarifolia, que causa intoxicações em pequenos ruminantes em todas as áreas visitadas. Stryphnodendron coriaceum pelas mortes que ocasiona é, aparentemente, a planta que causa maiores perdas econômicas na me- 
sorregião estudada. Enterolobium contortisiliquum também foi citada como causa importante de sinais digestivos, abortamentos e fotossensibilização em bovinos da região. Os entrevistados confirmaram a ocorrência de surtos de intoxicação em bovinos por Thiloa glaucocarpa no inicio do período chuvoso. Manihot spp. e Piptadenia macrocarpa são plantas cianogênicas apontadas como causa de mortes superagudas em bovinos. Outras plantas relatadas como tóxicas pelos entrevistados, mas sem que haja comprovação de sua toxicidade, foram Buchenavia tomentosa, Caesalpinia sp., Brunfelsia sp., Luetzelburgia sp., Hybantus ipecaconha, Phisalys angulata e Spondias luta. De acordo com os entrevistados os frutos de Buchenavia tomentosa causam sinais digestivos e abortos em caprinos, ovinos e bovinos. Produtores relatam surtos de intoxicação em caprinos que apresentam sinais digestivos e morte após a ingestão de favas de Luetzelburgia sp. Brunfelsia sp. é relatada como causa de alterações nervosas, no começo das chuvas, quando os animais ingerem as folhas e flores e os asininos são aparentemente mais afetados. Os frutos de Spondias luta foram mencionados como causa de diarréia em caprinos. Experimentos não publicados demonstraram a toxicidade de Brunfelsia sp. em ovinos e de Luetzelburgia sp. como causa de sinais digestivos e mortes em caprinos. Novos experimentos devem ser feitos para comprovar a toxicidade de outras plantas mencionadas nas entrevistas.

TERMOS DE INDEXACÃO: Plantas tóxicas, Ipomoea asarifolia, Stryphnodendron coriaceum, Enterolobium contortisiliquum, Thiloa glaucocarpa, plantas cianogênicas, intoxicação por planta.

\section{INTRODUÇÃO}

Plantas tóxicas de interesse pecuário ocasionam prejuízos relevantes aos produtores em todo o mundo. No Brasil, essas plantas causam perdas econômicas diretas e indiretas. Como perdas diretas podem ser citadas a morte de animais, baixo índice reprodutivo (abortos, malformações e infertilidade), baixa produtividade nos animais sobreviventes e outras alterações devidas a doenças transitórias, enfermidades subclínicas com diminuição da produção de leite, carne ou lã, e aumento da susceptibilidade a outras doenças devido à depressão imunológica. As perdas indiretas incluem os custos para o controle das plantas tóxicas nas pastagens, as medidas de manejo para evitar as intoxicações como a utilização de cercas e o pastoreio alternativo, a redução do valor da forragem devido ao atraso na sua utilização, a redução do valor da terra, a compra de gado para substituir os animais mortos, e os gastos associados ao diagnóstico das intoxicações e ao tratamento dos animais afetados (Riet-Correa \& Medeiros 2001, Riet-Correa et al. 2007).

As mortes anuais diagnosticadas em bovinos, por plantas tóxicas no Rio Grande do Sul, Santa Catarina e Bahia representam entre 10,6-14\% do total de mortes. Em ovinos no Rio Grande do Sul esta percentagem é de 7,2\%, (Riet-Correa \& Medeiros 2001, Riet-Correa et al. 2007). Com base nesses dados, estima-se que no Brasil mor- ram aproximadamente 1 milhão de bovinos em consequência das intoxicações por plantas (Riet-Correa et al. 2007).

O número de plantas tóxicas para ruminantes e equídeos no Brasil, vem crescendo consideravelmente. Atualmente, são conhecidas 117 plantas tóxicas pertencentes a 70 gêneros (Riet-Correa et al. 2007). Palicourea marcgravii é a planta tóxica de maior importância para os bovinos no Brasil, exceto no sul (Tokarnia et al. 2002). Pteridium aquilinium é uma das plantas tóxicas de grande importância no país, com maior impacto econômico nas regiões sul e sudeste (Anjos et al. 2008). No Rio Grande do Sul, Senecio spp. é a de maior importância em bovinos e Nierembergia veitchii em ovinos. Ateleia glazioviana tem grande importância em Santa Catarina e no Noroeste do Rio Grande do Sul. No Rio de Janeiro e Espírito Santo a planta de maior importância é Cestrum laevigatum (Tokarnia et al. 2002). Prejuízos econômicos em bovinos e ovinos, principalmente nas regiões sudeste e centrooeste, são causados pela intoxicação por Brachiaria spp. (Riet-Correa et al. 2007). Thiloa glaucocarpa e Mascagnia rigida são as principais plantas tóxicas do semiárido nordestino (Tokarnia et al. 2000, Riet-Correa \& Medeiros 2001, Riet-Correa et al. 2007). No Rio Grande do Norte, na região do Seridó Ocidental e Oriental, Ipomoea asarifolia e Aspidosperma pyrifolium são as plantas mais importantes como causa de intoxicação para ruminantes (Silva et al. 2006).

Segundo Silva et al. (2006), o estudo sistemático das plantas tóxicas em regiões com poucas pesquisas sobre as mesmas, aumenta consideravelmente o número de espécies tóxicas conhecidas e cita como exemplo um trabalho realizado na Paraíba, em que apenas oito plantas eram conhecidas até o ano 2000 , e depois da criação de um grupo de pesquisa em plantas tóxicas este número aumentou para 21 plantas tóxicas. No Estado do Piauí, nordeste do Brasil, o conhecimento das plantas tóxicas para animais de interesse pecuário foi iniciado na década de 50, onde algumas plantas foram testadas e reconhecidas como tóxicas (Tokarnia et al. 2000). Este trabalho teve por objetivo realizar um levantamento sobre as plantas tóxicas para ruminantes e equídeos na Mesorregião Norte do Piauí e discutir a importância delas na região.

\section{MATERIAL E MÉTODOS}

O levantamento sobre as principais plantas tóxicas de interesse pecuário na mesorregião do Norte Piauiense foi realizado abrangendo uma área total de 22.152,1 km² (IBGE 2007). Os municípios desta região estão agrupados em duas microrregiões que são a do Baixo Parnaíba Piauiense e do Litoral Piauiense (Fig.1). Predominam três classes vegetacionais que são o Cerrado, caracterizado por arbustos e árvores retorcidas e algumas gramíneas cobrindo o solo, a Floresta, composta por palmeiras, principalmente com espécies como a carnaúba, babaçu e buriti e a Mata dos Cocais onde predominam as mesmas palmeiras da Floresta (PLANAP 2006). O clima da região é tropical, com estações meteorológicas definidas (Medeiros 2004). A pluviosidade fica entre 1000-1600 mm/ano, 


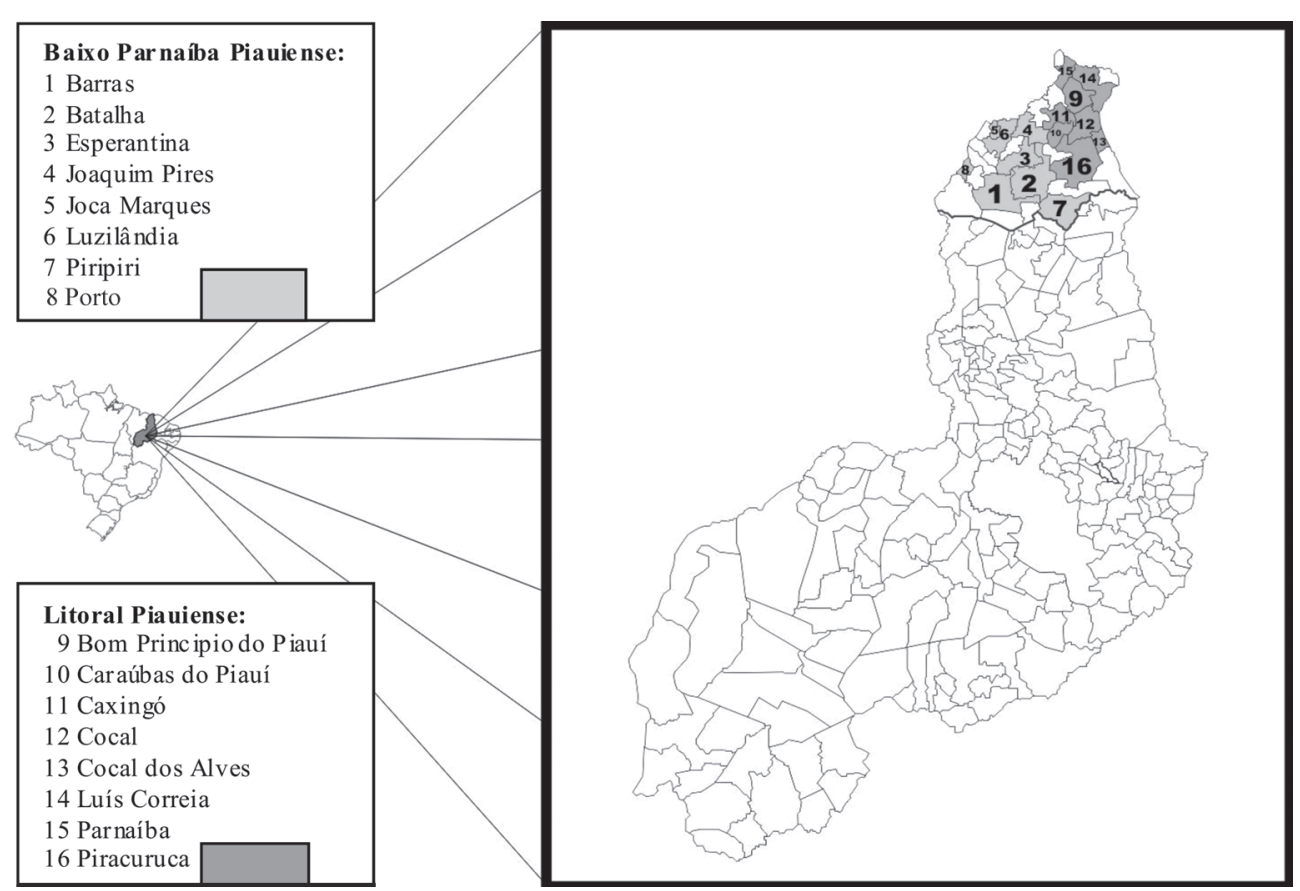

Fig.1. Municípios da Mesorregião Norte Piauiense, onde foram realizadas as entrevistas.

com chuvas de dezembro a abril e um período de seca que vai de maio a novembro, com temperaturas entre 19 e $36^{\circ} \mathrm{C}$ (Medeiros 2004). No que se refere à pecuária, a mesorregião do Norte Piauiense, é de caráter extensivo, se destacando o rebanho bovino com 302.173 animais e caprino com 240.029 animais (IBGE 2007).

Foram realizadas visitas a propriedades sendo entrevistados médicos veterinários, engenheiros agrônomos, técnicos agrícolas e produtores de 16 municípios pertencentes à mesorregião. Dos 71 entrevistados, oito foram veterinários, um agrônomo e seis técnicos agrícolas, que residiam ou prestavam assistência na região, e 56 produtores residentes nos municípios visitados. A entrevista foi baseada no preenchimento de três formulários semelhantes aos utilizados por Silva et al. (2006), entrevistando pelo menos quatro pessoas por município. No Formulário 1 foram incluídas as seguintes plantas: Stryphnodendron coriaceum, Thiloa glaucocarpa, Enterolobium contortisiliquum, Enterolobium gummiferum, Mimosa tenuiflora, Piptadenia macrocarpa, Manihot spp, Ricinus communis, Brachiaria spp., Crotalaria spp., Ipomoea asarifolia, Ipomoea carnea subsp. fistulosa, Indigofera suffruticosa, Ipomoea riedelli, Plumbago scandens, Sorghun vulgare, Mascagnia rigida, Nerium oleander, Aspidosperma pyrifolium, Lantana camara, Prosopis juliflora e Tephrosia cinerea. As plantas tóxicas de interesse pecuário citadas durante a aplicação dos questionários foram divididas de acordo com a principal ação patológica descrita por Tokarnia et al. (2000). As análises foram feitas de maneira descritiva.

\section{RESULTADOS}

O levantamento realizado apontou 15 plantas de toxicidade comprovada e sete conhecidas como tóxicas na região, mas sem comprovação científica. Os resultados são descritos de acordo com Silva et al. (2006) e as plantas subdivididas em grupos como descrito por Tokarnia et al. (2000).

\section{Ocorrência e epidemiologia de intoxicações por plantas já conhecidas como tóxicas}

\section{Plantas que causam perturbações nervosas}

Ipomoea asarifolia (salsa). Cinquenta e cinco entrevistados relataram intoxicações e mortes em caprinos e ovinos ou viram casos de intoxicação por esta planta. Um produtor afirmou que na região a salsa atinge mais ovinos do que outras espécies, devido, provavelmente, ao sistema de criação extensivo, já que os bovinos são criados no sistema de semi-confinamento. Outro produtor relatou a morte de vários ovinos devido à salsa, mas não soube precisar o numero de animais. Um entrevistado relatou a morte de 30 cabritos e outro mencionou que 15 ovelhas do seu rebanho morreram nos últimos seis anos devido à salsa. Segundo um técnico agrícola, a salsa afeta mais os animais no final da época de seca, onde o alimento é escasso, período em que as ovelhas se alimentam da planta verde e os borregos seriam afetados através do leite. $O$ mesmo relatou a intoxicação de 15 borregos em um rebanho de 90 ovinos em dezembro de 2008. Acrescentou que os borregos que comem ração têm mais chance de se recuperar por que podem ser apartados da mãe deixando de ingerir leite; a mortalidade é maior nos mais novos que continuam a alimentar-se com leite. Um criador relatou a morte de três ovinos de um rebanho de 200 animais há mais ou menos seis anos devido à salsa murcha. Outro criador mencionou a morte de 25 borregos de um rebanho de 150 animais por causa da planta nos últimos cinco anos. O sinal clínico relatado por todos os entrevistados nos casos de intoxicação pela salsa é o tremor, pelo que muitos produtores conhecem a intoxicação como "doença do treme". Os animais se recuperam após serem retirados dos locais onde se encontra a planta. 
Ricinus communis. Um entrevistado mencionou a intoxicação por folhas de mamona em dois bovinos, dos quais um morreu e o outro se recuperou. Segundo o criador, os animais apresentavam tremores. Outro entrevistado relatou conhecer o efeito tóxico da planta e mencionou já ter visto casos de intoxicação, afirmando que a planta é tóxica apenas quando as folhas estão murchas. Um proprietário relatou a morte de quatro vacas após terem ingerido a planta e apresentado como sinais clínicos somente timpanismo e salivação.

\section{Plantas que afetam o sistema digestivo \\ Stryphnodendron coriaceum (barbatimão, barbati-} mão-do-Nordeste, barbatimão-do-Piauí). De acordo com os criadores e veterinários o período de intoxicação é de julho a setembro quando as favas caem. Os principais sinais clínicos mencionados foram parada ruminal e perda progressiva de peso. A planta é mais comum em chapadas. Treze entrevistados citaram casos de intoxicação por essa planta na região. Houve um relato de morte de dois a cinco bovinos por ano por causa do consumo da fava do barbatimão. Alguns produtores citaram ainda que os animais adquiridos de outras áreas são mais susceptíveis a planta do que os da região, fato esse mencionado por outro produtor. Outro entrevistado relatou a intoxicação de 20 bovinos com a morte de dois animais e abortamento no terço final da gestação de outras quatro vacas em um rebanho de 40 animais em agosto de 2008. De acordo com esse entrevistado, os animais foram retirados do local de onde se encontravam as plantas e tratados com glicose e óleo, assim que percebeu o emagrecimento rápido de um dos animais, mas os animais morreram 15 dias após serem retirados da área que se encontravam as plantas. Um dos entrevistados mencionou que o barbatimão é a planta tóxica de maior importância dessa região. Um veterinário da microrregião do Baixo Parnaíba Piauiense relatou que $S$. coriaceum é a principal planta tóxica da região e cita como um dos sinais clínicos a fotossensibilização em bovinos que não morrem pela ingestão da fava. Os entrevistados afirmaram que o número de animais intoxicados no passado era bem maior que atualmente e que os casos de intoxicação pelo barbatimão vem diminuindo devido ao corte das árvores encontradas na propriedade.

Enterolobium contortisiliquum (tamboril, timbaúba, timbaúva, orelha-de-negro). Vinte e sete entrevistados relataram ter visto algum caso de intoxicação pela planta em caprinos e bovinos. Um entrevistado relatou a intoxicação de 14 bovinos, com a morte de oito e a recuperação de seis, em um rebanho de 60 animais em agosto de 2006. Os casos aconteceram quando os animais foram retirados de uma área de barbatimão e colocados em outra sem o conhecimento da existência de tamboril. Ao final de duas semanas foi encontrada uma vaca morta e outras com sinais de intoxicação. Os animais apresentavam-se magros, sem se alimentar e bebendo pouco. Fotossensibilização foi observada nos animais que sobreviveram. Um veteri- nário relatou ter visto mais de 15 casos de intoxicação em bovinos em anos anteriores. Um produtor mencionou terem morrido três novilhas devido à planta no ano de 2007 com sintomatologia de fezes com sangue. Outros três entrevistados relacionam casos de abortamento causados pela planta. Um criador relatou que cinco vacas de um total de 15, abortaram devido ao tamboril em 2007. Outro relatou a morte de um caprino devido à fava do tamboril. Um entrevistado relatou que de oito vacas prenhes, seis abortaram devido à planta em setembro de 2008 e relacionou casos de abortamento em bovinos com a planta. Todos afirmaram que o período da fava do tamboril começa entre setembro/outubro e acaba em novembro.

\section{Planta nefrotóxica}

Thiloa glaucocarpa (sipaúba, vaqueta). A planta foi mencionada como tóxica por sete entrevistados. Um relatou terem morrido 19 bovinos em um rebanho de 200 animais logo nas primeiras chuvas em 2007, apresentando apatia, anorexia, edema da região posterior da coxa (popa inchada), peito e barbela e língua amarelada. Outro entrevistado relatou que em dezembro de 2008 , logo nas primeiras chuvas, 10 bovinos leiteiros de um rebanho de 40 animais adoeceram devido à planta, e desses dez, quatro morreram em 3-4 dias. Todos apresentaram edema na região posterior da coxa, e os que sobreviveram apresentaram tremores musculares por um período de três semanas. Outro entrevistado relatou que a planta é a primeira a brotar no inverno, que a mesma só é tóxica quando está murcha e relata que na década de 90 , um surto em 50 bovinos de corte em um rebanho de 250 animais, com a morte de 30 deles. Os animais apresentaram anorexia, atonia ruminal, incoordenação motora, decúbito esternal, edema da região posterior da coxa e de barbela e dificuldade de urinar. Foi observado ao abrir um animal morto, presença de muito líquido na cavidade abdominal. Um entrevistado relatou casos de morte e abortos em bovinos devido à planta. Dois produtores relataram que os animais alimentam-se da sipaúba no começo das chuvas e não apresentam problema, ressaltando que a planta ajuda a manter o gado quando não há alimentação suficiente.

\section{Plantas hepatotóxicas}

Brachiaria decumbens (capim-braquiária). Dois entrevistados relataram ter sabido de casos de intoxicação por braquiária em bovinos e ovinos, mas não souberam precisar a data e os sinais clínicos.

Crotalaria spp. (guizo-de-cascavel, feijão-de-guizo, chocalho-de-cobra, gergelim-bravo). Dois entrevistados relataram ter visto casos de intoxicação pela planta em bovinos. Um produtor responsabilizou a planta por um caso de aborto em bovino.

\section{Plantas cianogênicas}

Manihot spp. (maniçoba). Onze entrevistados relataram casos de intoxicação pela planta. Ocorreu um surto em março de 2008 em uma área em que Manihot spp. foi 
cortada junto com outras árvores que estavam sendo cortadas para produção de lenha. Foram intoxicadas 15 vacas de um rebanho leiteiro de 150 animais; sete morreram e oito se recuperaram. Segundo o veterinário que assistiu à propriedade, os animais afetados apresentavam anorexia, tremores musculares, incoordenação motora e insuficiência respiratória.

Piptadenia macrocarpa (angico-preto). Um entrevistado relatou a morte de cinco novilhas no final da década de 90. Outro tem a planta como a principal planta tóxica da sua fazenda, mencionando a morte de três bovinos e 10 caprinos no verão de 2007 e de duas novilhas na mesma época em outra fazenda. Relatou ainda que todos os anos morrem animais por causa da planta. Os sinais clínicos relatados pelos entrevistados são incoordenação motora e insuficiência respiratória seguidos de morte após curso clínico rápido. Os casos de ingestão da planta, segundo os entrevistados, ocorrem sempre de forma acidental, geralmente depois de chuvas com ventos fortes quando galhos da árvore se quebram e os animais se alimentam deles. Um entrevistado suspeitou que a rama nova murcha do angico preto tenha sido a causa de um aborto em bovino.

\section{Plantas que causam malformações}

Mimosa tenuiflora (jurema-preta). Segundo os entrevistados a planta existe na região, mas apenas um produtor mencionou casos de malformações em cabritos devido à planta.
Nenhum dos entrevistados conhecia Enterolobium gummiferum (tamboril, orelha-de-onça), Indigofera suffruticosa (anil), Ipomoea riedelli (anicão), Plumbago scandens (louco), Sorghun vulgare (sorgo), Mascagnia rigida (tinguí) e Nerium oleander (espirradeira).

Aspidosperma pyrifolium (pereiro), Lantana camara (chumbinho), Prosopis juliflora (algaroba) e Tephrosia cinerea (anil, falso-anil), foram citadas por alguns entrevistados como existentes na região, mas sem o conhecimento de toxicidade das mesmas. Esta última foi citada por um entrevistado e diz ser conhecida na região como feijãode-rolinha. O produtor relata que a planta invade o pasto, mas que nunca teve casos de intoxicação, devido a pouca palatabilidade da mesma. Ipomoea carnea subsp. fistulosa é encontrada na região, apesar de não ter sido citada pelos entrevistados como tóxica.

\section{Plantas relatadas como tóxicas pelos entrevistados, mas sem comprovação de sua toxicidade}

Buchenavia tomentosa (mirindiba, birindiba) (Fig.2). A planta foi citada como tóxica para caprinos, ovinos e bovinos por vinte entrevistados, sendo a responsável pelo maior número de abortamentos mencionado no presente estudo. De acordo com os entrevistados os animais se alimentam avidamente dos frutos que caem de agosto a outubro. Um produtor relatou que a quantidade de frutos varia a cada ano; se em um ano a planta produz mais, no ano seguinte a produção é menor. Outro entrevistado relatou um surto em um rebanho de 160 bovinos em agosto de 2007 e descreveu

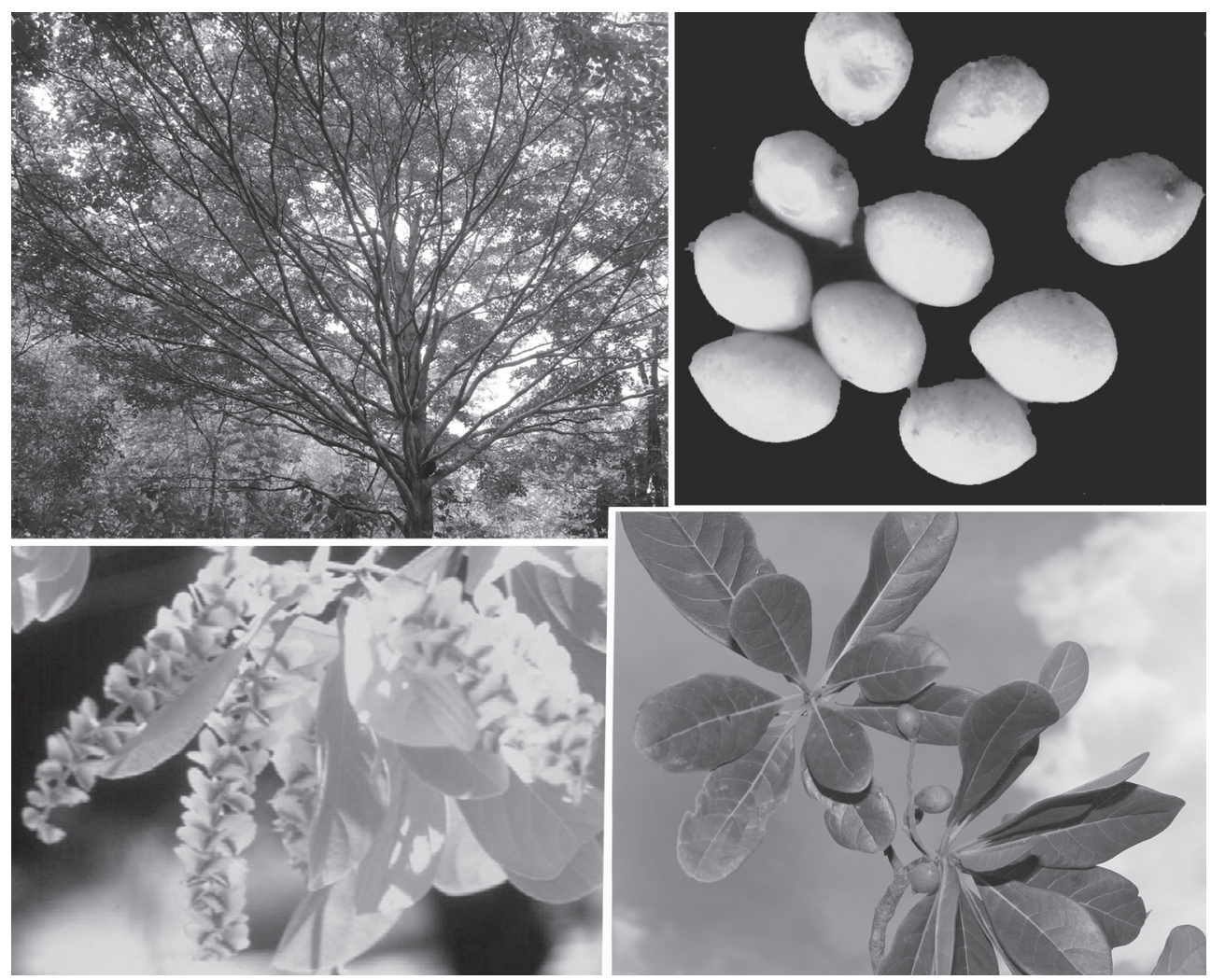

Fig.2. Buchenavia tomentosa. 


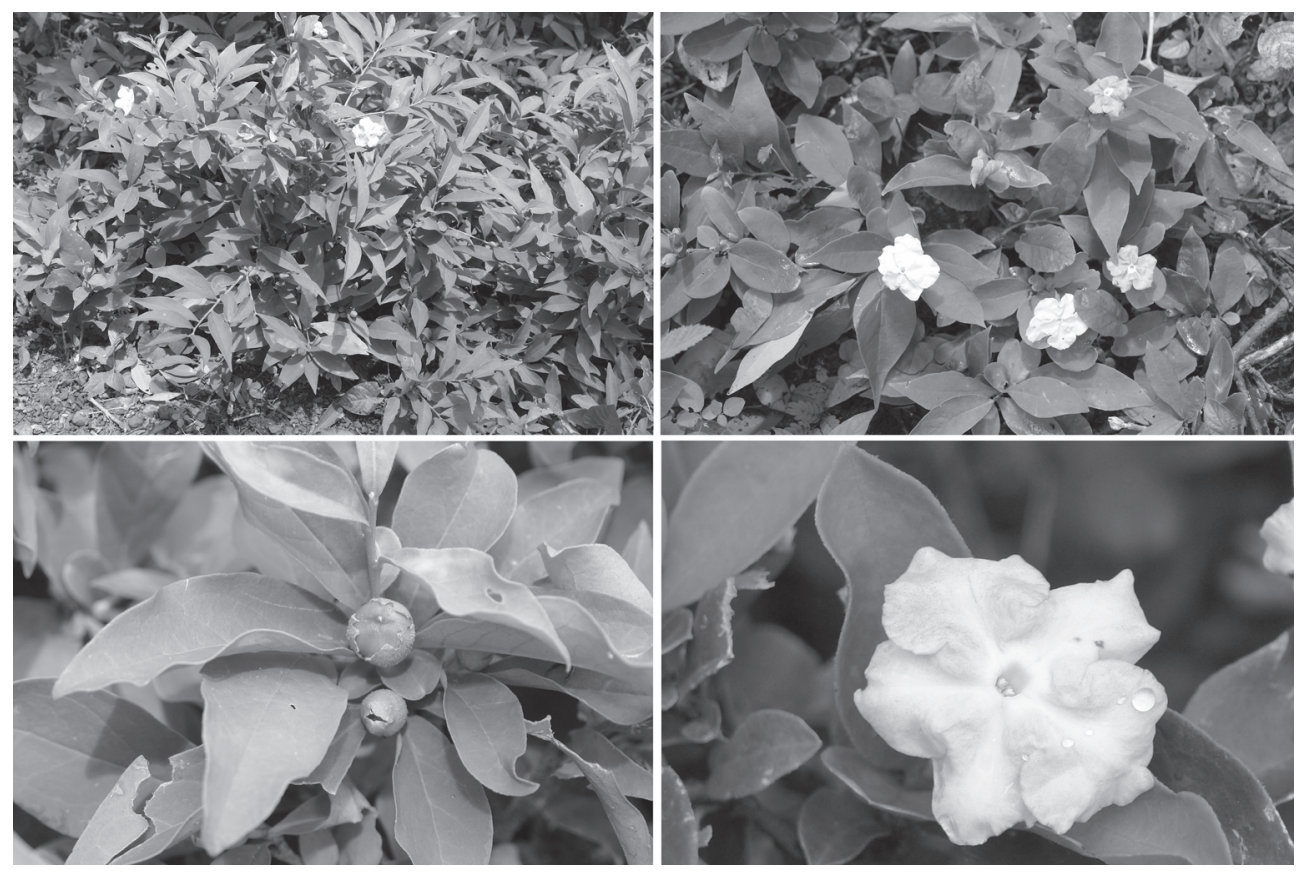

Fig.3. Brunfelsia sp.

como único sinal clínico a perda de peso. Os sinais clínicos relatados por outros entrevistados foram diarréia, focinho seco, fraqueza, perda de peso, nascimento de animais fracos e abortamento. Alguns animais morrem. Cinquenta casos de aborto teriam ocorrido em um rebanho de 350 caprinos e 12 bovinos teriam abortado no terço final da gestação. Um entrevistado relatou ainda a morte de oito caprinos num rebanho de 100 animais na década de 80 .

Caesalpinia sp. (catingueira). Segundo alguns produtores a intoxicação ocorre nos meses de agosto a setem- bro quando o pasto é escasso, período em que os animais se alimentam das favas e se intoxicam. Dois entrevistados afirmaram que a catingueira é causadora de malformações em caprinos. Foram relatados também outros sinais de intoxicação como salivação, abortamento em caprinos, e morte de bovinos e caprinos. Lesões no omaso são a causa da morte dos animais segundo alguns veterinários entrevistados.

Brunfelsia sp. (manacá) (Fig.3). Dezoito entrevistados conhecem a planta como tóxica. As intoxicações ocor-
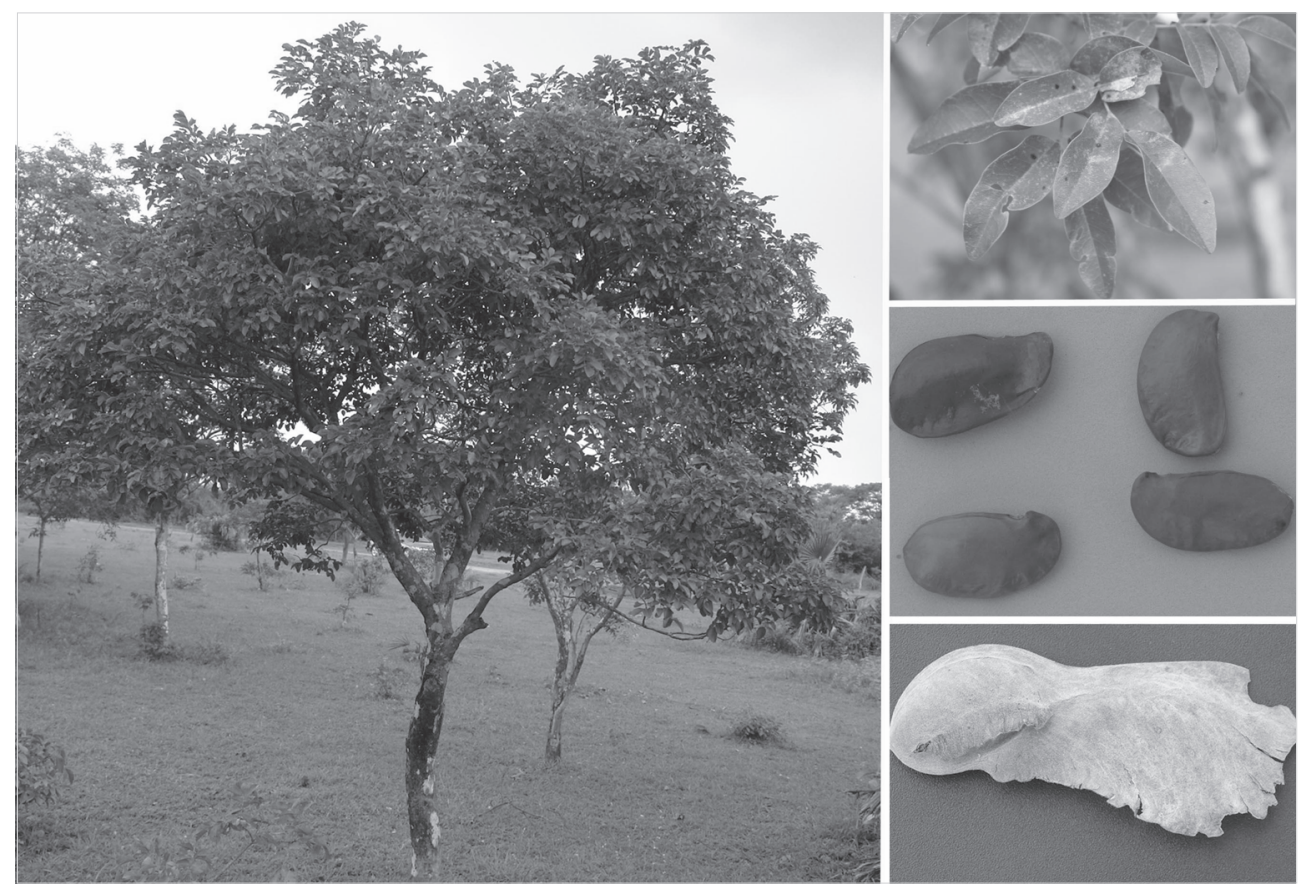

Fig.4. Luetzelburgia sp. 
rem sempre no começo das chuvas, período que varia de dezembro a março, quando os animais ingerem as folhas e flores. De acordo com alguns produtores o manacá só é tóxico quando está florindo, sendo que o cheiro atrai os animais. Os asininos são os animais mais afetados, pois os produtores afirmam que é mais palatável para essa espécie, mas bovinos, ovinos e caprinos também se intoxicam com a planta. Causa sinais nervosos: os animais correm de um lado para outro, rodando em círculos ou cambaleando e podem morrer se não forem retirados do local onde se encontra a planta.

Luetzelburgia sp. (pau-mocó) (Fig.4). Três entrevistados citaram as favas desta planta como tóxicas para caprinos. As intoxicações acontecem em agosto/setembro, período em que a fava amadurece e cai da planta. Um entrevistado relatou que os animais ingerem a planta e a intoxicação causa aborto se o caprino ingerir em pequena quantidade e timpanismo e morte se for ingerido em maior quantidade. Outro entrevistado mencionou que a planta não é palatável, mas que leva a morte mesmo ingerindo poucas favas.

Hybanthus ipecaconha (papaconha) (Fig.5). Foi citada por três entrevistados como tóxica. O período de intoxicação é de abril a começo de junho. Os sinais clínicos mencionados foram diarréia, perda de equilíbrio, abortamento e morte de caprinos e bovinos.

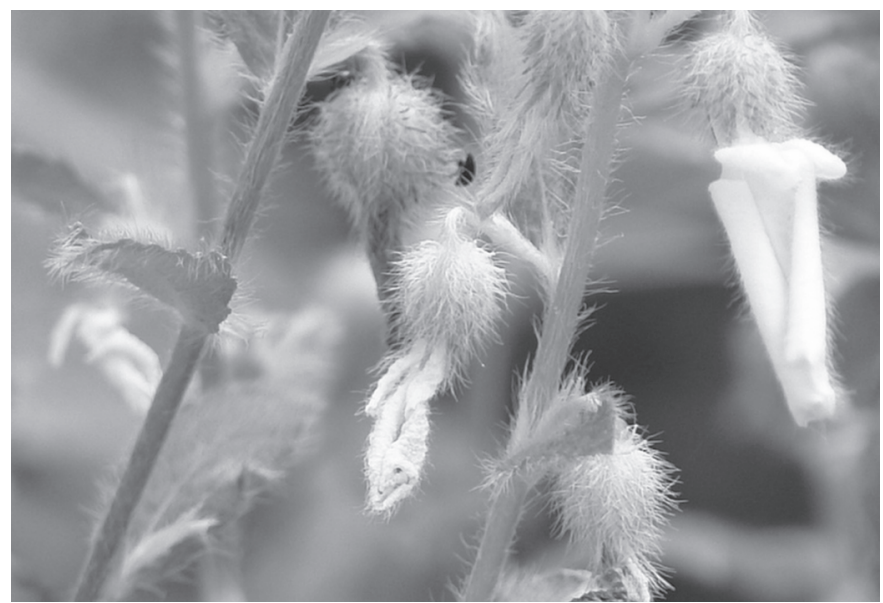

Fig.5. Hybantus ipecaconha.

Phisalys angulata (canapum, canapú). Um entrevistado relatou que a planta é abortiva para caprinos e ovinos, as intoxicações ocorrem no período de chuva e a planta tem boa palatabilidade para esses animais.

Spondias luta (cajá). Três entrevistados citaram os frutos dessa planta como tóxicos para caprinos, com sinais clínicos de diarréia, fraqueza e morte. Um entrevistado relatou que em 2007 morreram cinco caprinos de um rebanho de aproximadamente 100 animais e que no ano de 2008 cortou nove pés de cajá para evitar mortes dos animais em sua propriedade. Outro entrevistado relatou que os caprinos gostam da fruta e que não comem outra coisa enquanto não forem retirados do local onde se encontra a fruta e que todos os anos morrem em média cinco caprinos de sua propriedade devido à planta.

\section{DISCUSSÃO E CONCLUSÕES}

As plantas apontadas como tóxicas pelos entrevistados, com maior frequência, na região estudada, e que têm comprovação experimental, foram Ipomoea asarifolia, Stryphnodendron coriaceum, Enterolobium contortisiliquum, Manihot spp. e Thiloa glaucocarpa. Também foram relatados como tóxicas, porém aparentemente com menor importância Ricinus communis, Piptadenia macrocarpa, Crotalaria spp. e Brachiaria spp. Outras plantas relatadas como tóxicas, mas sem comprovação de sua toxicidade foram Buchenavia tomentosa, Caesalpinia sp., Brunfelsia sp., Luetzelburgia sp., Hybantus ipecaconha, Phisalys angulata e Spondias luta. Devem ser realizados trabaIhos experimentais com estas plantas, a fim de comprovar a veracidade das informações obtidas.

Das plantas tóxicas com comprovação científica, Ipomoea asarifolia é a que mais intoxica caprinos e ovinos na região, na época seca, quando o alimento não é suficiente no sistema de criação extensivo. Segundo Tokarnia et al. (2000) e Araújo et al. (2008) a planta é menos tóxica no período das chuvas e causa intoxicação com a folha verde ou seca. Os tremores, relatados por todos os entrevistados, foram o principal sinal clínico, sendo que estes desaparecem quando os animais deixam de ingerir a planta. $O$ tratamento é a retirada do animal do local onde ocorre a salsa. O relato de que os cordeiros lactentes são afetados através do leite, não foi comprovado experimentalmente (Araújo et al. 2008), entretanto, há evidências de que a toxina da planta seja eliminada através do leite (Riet-Correa et al. 2006). Deve ser feito o diagnóstico diferencial com outras plantas que afetam o sistema nervoso, principalmente Ipomoea carnea que, apesar de encontrada na região, não foi relatada como tóxica.

Stryphnodendron coriaceum parece ser responsável pelas maiores perdas econômicas em bovinos na mesorregião. A intoxicação ocorre no período da seca, quando suas favas caem e os animais as ingerem. Chama atenção o relato da maior susceptibilidade de animais oriundos de outras regiões, onde não ocorre a planta, o que pareceria ser um fator importante para a ocorrência da intoxicação, além da fome. Tokarnia et al. $(2000,2002)$ citam que ocorrem alterações gastrointestinais nas intoxicações por essa planta; isto também foi encontrado neste trabalho, sendo os principais sinais clínicos a atonia ruminal e o emagrecimento. Os mesmos autores descrevem que fotossensibilização e aborto, podem ocorrer quando os animais sobrevivem à intoxicação. O número de intoxicações por essa planta vem diminuindo a cada ano, devido ao corte da mesma pelos produtores. A forma mais adequada de controle é retirar os animais dos locais onde ocorrem as favas no período de escassez de alimento.

As favas do Enterolobium contortisiliquum mostraramse importante causa de intoxicação para bovinos e, provavelmente, para caprinos. Os sinais clínicos apontados 
pelos entrevistados foram diarréia com sangue, aborto e, em alguns casos, fotossensibilização, semelhantes aos descritos anteriormente (Tokarnia et al. 2000, Riet-Correa et al. 2006). Benício et al. (2005) relatam que caprinos apresentam sinais digestivos e abortos, sem fotossensibilização.

Alguns entrevistados mencionaram a intoxicação por Thiloa glaucocarpa, causando surtos, no início das chuvas. Ao contrário do que foi relatado por um produtor sobre a ocorrência da intoxicação apenas quando a folha está murcha, Tokarnia et al. (1981) verificaram que a intoxicação ocorre quando a rama ainda é viçosa e que não ocorrem novos casos de intoxicação quando as folhas amadurecem. Os sinais clínicos e as lesões macroscópicas mencionadas pelos entrevistados, como edema da região glútea (popa inchada) e barbela e líquido na cavidade abdominal, são semelhantes aos mencionados anteriormente (Tokarnia et al. 1981). Os animais que não apresentam edemas são denominados venta seca. A morte ocorre em cinco a 20 dias após a ingestão da planta (Tokarnia et al. 1981).

Manihot spp. e Piptadenia macrocarpa são plantas cianogênicas apontadas como tóxicas para bovinos, provocando mortes após um curso clínico superagudo. $\mathrm{Na}$ intoxicação pelo angico preto os entrevistados relatam que os animais só ingerem a planta após a queda de galhos após chuvas ou ventos fortes. Esta característica é relatada em outras regiões do semiárido (Tokarnia et al. 2000, Riet-Correa et al. 2006). O diagnóstico deve ser confirmado com o resultado positivo ao teste do papel picrosódico e a resposta ao tratamento (Amorim et al. 2005). Deve ser considerado o diagnóstico diferencial com outras plantas cianogênicas, como a intoxicação por Mascagnia rigida (Tokarnia et al. 2000) e com a intoxicação por nitritos e nitratos (Medeiros et al. 2003).

Mimosa tenuiflora, apenas apontada por um entrevistado como causadora de malformações em caprinos, causa malformações em caprinos, ovinos e bovinos no semiárido (Pimentel et al. 2007). As favas de Caesalpinia sp. são responsabilizadas por produtores por malformações em caprinos. O efeito teratogênico desta planta deve ser objeto de estudo, já que, segundo alguns entrevistados, malformações também ocorrem em áreas livres da jurema preta. Caesalpinia sp. também foi apontada como causa de alterações no trato gastrintestinal, que poderiam ser devidas ao consumo das favas com alto conteúdo de fibra de baixa digestibilidade. Tokarnia et al. (2000) fornecem dados sobre experimentos com $C$. bracteosa e C. ferrea em bovinos com resultados negativos.

Ricinus communis foi relatada por alguns entrevistados como tóxica. No Nordeste há numerosos históricos de intoxicação pelas folhas desta planta (Tokarnia et al. 2002); no entanto, casos de intoxicação espontânea não têm sido relatados. As folhas e o pericarpo do fruto que têm como principio tóxico a ricinina causam um quadro clinico neuromuscular e as sementes que possuem ricina afetam principalmente o tubo digestivo (Tokarnia et al. 2000).
Entre as plantas de toxicidade não confirmada, Buchenavia tomentosa foi a mais frequentemente mencionada como tóxica. De acordo com os entrevistados as sementes da planta por serem muito palatáveis são consumidas em grandes quantidades causando sinais digestivos e abortos em caprinos, ovinos e bovinos. Em um estudo preliminar esta planta foi administrada em doses únicas de 10, 20 e 40 $/ \mathrm{kg}$ de peso corporal a grupos de duas cabras em gestação; uma das cabras que ingeriu $40 \mathrm{~g} / \mathrm{kg}$ abortou (Bandeira 2006). Novos experimentos são necessários para comprovar o efeito abortivo ou outras alterações causadas por esta planta.

As favas de Luetzelburgia sp. foram mencionadas como tóxicas para caprinos. A toxicidade desta planta, com sinais digestivos e lesões do trato gastrintestinal foi comprovada experimentalmente em caprinos que morreram após a ingestão de $2,5 \mathrm{~g}$ de favas por $\mathrm{kg}$ de peso corporal. Caprinos que ingeriram $1 \mathrm{~g} / \mathrm{kg}$ apresentaram sinais digestivos e se recuperaram (Mello 2009).

Brunfelsia sp. foi citada como tóxica, causando sinais nervosos no começo das chuvas, quando os animais ingerem as folhas e flores. Em experimento com um ovino, o animal apresentou sinais nervosos com uma única dose de $9,9 \mathrm{~g} / \mathrm{kg}$ e se recuperou (Riet-Correa 2008). Aproximadamente um mês depois foram realizados novos experimentos em ovinos com doses repetidas de 10 e $20 \mathrm{~g} / \mathrm{kg}$, mas não se conseguiu reproduzir a doença (Silva 2008) Esses resultados estão de acordo com o mencionado pelos entrevistados, que mencionaram que a planta só é tóxica por um período curto após o início das chuvas.

Os frutos de Spondias luta foram mencionados como palatáveis e tóxicos para caprinos, sendo a diarréia o principal sinal clínico, podendo haver morte. Pelas descrições trata-se de uma planta que provoca alterações gastrintestinais em consequência da ingestão de grandes quantidades e experimentos devem ser conduzidos, para que se prove a veracidade dessas informações.

Hybantus ipecaconha, de acordo com os entrevistados, causa diarréia e morte de caprinos e bovinos entre os meses de abril e maio. Em um experimento com a planta coletada no Piauí foram reproduzidos sinais principalmente digestivos (anorexia, parada ruminal, abdômen volumoso, sede, catarro pelas narinas, taquicardia acentuada, respiração ofegante e inquietação) e morte com doses de 20 e $30 \mathrm{~g}$ de planta por kg de peso; no entanto em outros experimentos com a planta procedente de outras regiões não foi constatada toxicidade com doses únicas de $10-40 \mathrm{~g} / \mathrm{kg}$ ou com doses repetidas de $5 \mathrm{~g} / \mathrm{kg}$ de planta seca durante 47 dias (Tokarnia 1997). Tanto os históricos como os resultados desses experimentos sugerem que Hybantus ipecaconha ocasionalmente apresenta toxicidade.

Phisalys angulata foi relatada como causa de abortos em caprinos e ovinos; no entanto, em experimentos realizados com caprinos na Paraíba os animais não abortaram com doses de até $40 \mathrm{~g} / \mathrm{kg}$ de peso corporal (RietCorrea 2003, dados não publicados). Um fato que chama a atenção nas entrevistas é as numerosas plantas que 
são responsabilizadas por causarem abortos em ruminantes. Uma situação semelhante ocorre na Paraíba, onde diversas plantas foram testadas em caprinos, mas a única na qual se comprovou a capacidade abortiva foi Aspidosperma pyrifolium (Riet-Correa \& Méndez 2007).

Um fato interessante é que, semelhante ao que ocorre em outras regiões do nordeste, muitos produtores mencionam plantas que somente seriam tóxicas quando murchas. Esse fato não foi comprovado até o momento para nenhuma das plantas mencionadas. O que provavelmente acontece é que os produtores cortam as plantas, muitas vezes para o consumo dos animais, e estas murcham. Pelo fato de estarem ao alcance dos animais, às vezes em grandes quantidades, causam intoxicação, não pelo fato de estarem murchas.

Os resultados deste trabalho, apesar das limitações no referente às informações mencionadas pelos proprietários, são de muito valor, não só para conhecer a importância das diferentes intoxicações por plantas na região, mas também, por ter aportado importantes informações e hipótese a serem comprovadas em futuros projetos de pesquisa.

Agradecimentos.- Aos Institutos do Milênio (CNPq, Proc. 420012/20052), INCT para o Controle das Plantas Tóxicas ( Proc. 573534/2008-0) e Programa de Pós-Graduação em Ciência Animal, UFPI. Ao professor Odací F. de Oliveira, da Universidade Federal Rural do Semi-Árido, pela identificação botânica das plantas.

\section{REFERÊNCIAS}

Anjos B.L., Irigoyen L.F., Fighera R.A., Gomes A.D., Kommers G.D. \& Barros C.S.L. 2008. Intoxicação aguda por samambaia (Pteridium aquilinum) em bovinos na Região Central do Rio Grande do Sul. Pesq. Vet. Bras. 28:501-507.

Amorim S.L., Medeiros R.M.T. \& Riet-Correa F. 2005. Intoxicação experimental por Manihot glaziovii (Euphorbiaceae) em caprinos. Pesq. Vet. Bras. 25(3):179-187.

Araújo J.A.S., Riet-Correa F., Medeiros R.M.T., Soares M.P., Oliveira D.M. \& Carvalho F.K.L. 2008. Intoxicação experimental por Ipomoea asarifolia (Convolvulaceae) em caprinos e ovinos. Pesq. Vet. Bras. 28(10):488-494.

Bandeira Y.C.M. 2006. Plantas tóxicas e casos de intoxicação na microrregião de Balsas, sul do Maranhão. Monografia de Conclusão de Curso, Centro de Saúde e Tecnologia Rural, Universidade Federal de Campina Grande, Patos, PB. 53p.

Benício T.M.A., Nardelli M.J., Nogueira F.R.B., Araújo J.A.S. \& RietCorrea F. 2005. Intoxication by the pods of Enterolobium contortisiliquum in goats, p.67-71. In: Panter K.E., Wierenga T.L. \& Pfister J.A. (Eds), Poisonous Plants: Global research and solutions. CAB International, Wallingford.

IBGE 2007. Diretoria de Pesquisas, Coordenação de Agropecuária,
Pesquisa da Pecuária Municipal 2007. Instituto Brasileiro de Geografia e Estatística, Rio de Janeiro.

Medeiros R.M. 2004. Estudo agrometeorológico para o Estado do Piauí. Secretaria do Meio Ambiente e Recursos Hídricos do Piauí, Teresina, p.88-112.

Medeiros R.M.T., Riet-Correa F., Tabosa I.M., Silva Z.A., Barbosa R.C., Marques A.V.M.S. \& Nogueira F.R.B. 2003. Intoxicação por nitratos e nitritos em bovinos por ingestão de Ehinochloa polystachya (capimmandante) e Pennisetum purpureum (capim-elefante) no sertão da Paraíba. Pesq. Vet. Bras. 23(1):17-20.

Mello G.W.S. 2009. Plantas tóxicas para ruminantes e eqüídeos no Norte Piauiense. Dissertação de Mestrado em Ciência Animal, Centro de Ciências Agrárias, Universidade Federal do Piauí, Teresina, PI. 73p.

Pimentel L.A., Riet-Correa F., Gardner D.R., Panter K., Dantas A.F.M., Medeiros R.M.T., Mota R.A. \& Araújo J.A.S. 2007. Mimosa tenuiflora as a cause of malformations in ruminants in the northeastern Brazilian semiarid rangelands. Vet. Pathol. 44:928-931.

PLANAP 2006. Plano de Ação para o desenvolvimento integrado da Bacia do Parnaíba. Disponível em http://www.codevasf.gov.br/ programas acoes/plano-de-desenvolvimento-do-parnaiba-1/arquivosplanap/?searchterm=planap. Acesso em 31 de março de 2009.

Riet-Correa F. \& Medeiros R.M.T. 2001. Intoxicações por plantas em ruminantes no Brasil e no Uruguai: importância econômica, controle e riscos para a saúde pública. Pesq. Vet. Bras. 21(1):38-42.

Riet-Correa F., Medeiros R.M.T., Tokarnia C.H. \& Döbereiner J. 2007. Toxic plants for livestock in Brazil: Economic impact, toxic species, control measures and public health implications, p.2-14. In: Panter K.E., Wierenga T.L. \& Pfister J.A. (Eds), Poisonous Plants: Global research and solutions. $C A B$ International, Wallingford.

Riet-Correa F., Medeiros R.M.T. \& Dantas A.F. 2006. Plantas Tóxicas da Paraíba. SEBRAE, João Pessoa. 54p.

Riet-Correa F. \& Méndez M.C. 2007. Intoxicações por plantas e micotoxicoses, p.99-221. In: Riet-Correa F., Schild A.L., Lemos R.A.A. \& Borges J.R.J. (Eds), Doenças de Ruminantes e Eqüídeos. Vol.2. 3a ed. Palloti, Santa Maria.

Riet-Correa F. 2008. Comunicação pessoal (Universidade Federal de Campina Grande, Patos, PB).

Silva D.M., Riet-Correa F., Medeiros R.M.T. \& Oliveira O.F. 2006. Plantas tóxicas para ruminantes e eqüídeos no Seridó Ocidental e Oriental no Rio Grande do Norte. Pesq. Vet. Bras. 26(4):223-236.

Silva S.M.M. 2008. Comunicação pessoal (Universidade Federal do Piauí, Teresina, $\mathrm{PI})$.

Tokarnia C.H. 1997. Intoxicação por Hibanthus ipecaconha (fam. Violaceae), "papaconha" ou "ipecaconha" em bovinos. Dados não publicados. $8 p$.

Tokarnia C.H., Döbereiner J. \& Peixoto P.V. 2000. Plantas Tóxicas do Brasil. Editora Helianthus, Rio de Janeiro. 310p.

Tokarnia C.H., Döbereiner J. \& Peixoto P.V. 2002. Poisonous plants affecting livestock in Brazil: Review. Toxicon 40:1635-1660.

Tokarnia C.H., Döbereiner J., Canella C.F.C., Couceiro J.E.M., Silva A.C.C. \& Araújo F.V. 1981. Intoxicação de bovinos por Thiloa glaucocarpa (Combretaceae), no nordeste do Brasil. Pesq. Vet. Bras. 1(4):111-132. 